\title{
A Urgência e o Direito de Família (As Chamadas Medidas Provisionais do artigo 888 do $\mathrm{CPC}$ )
}

\section{Carlos EAllento Ethrara de Oliveina}

Professor Titular de Direito Processual Civil dos Cursos de Graduação e Pós-Graduação da Faculdade de Direito da UFRGS. Doutor em Direito pela USP. Desembargador do TJRGS.

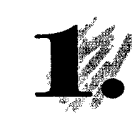

Tão premente se apresenta em tema de direito de família a solução rápida do litígio, por envolver esse ramo do direito, em regra, valores sensíveis e de grande significado emocional, às vezes materiais, vinculados à realização de necessidades íntimas do ser humano, que exige no plano processual uma pronta resposta da jurisdição. $O$ acesso de febre, sintoma de doenças mais graves, deve ser combatido prontamente para que a saúde jurídica dos integrantes da família volte às boas. Daí, a adequação a esse campo da tutela de urgência e de outras providências assemelhadas tendentes à rápida solução do litígio decorrente da relação familiar. Chama a atenção, nesse contexto, não tenham os operadores do direito brasileiro ainda se dado conta da importância decisiva das medidas provisionais do artigo 888 do CPC.

Talvez a razão para o fenômeno este. ja na circunstância bastante conhecida de que nos dias atuais virou moda adotar-se em caso de urgência, inclusive na área do direito de família, a tutela antecipatória do artigo 273. Não há dúvida de que a satisfação provisória, mormente se dispensada initio litis, é a que melhor se ajusta aos valores envolvidos em casos tais, pois capaz de interferir no próprio plano do direito material e antecipar os efeitos da futura sentença de mérito. Somente assim será possível prevenir o dano, porquanto nessas hipóteses não basta apenas conservar para afastar a insatisfação decorrente do estado antijurídico, revelando-se necessária a antecipação, parcial ou total, dos próprios efeitos materiais da sentença a ser proferida no processo de conhecimento. Tudo tem a sua fonte na própria natureza do periculum in mora que, em tais hipóteses, constitui-se não pelo temido desaparecimento dos meios necessários à formação e execução da providência principal, e sim, precisamente, pela permanência do estado de insatisfação do direito, objeto do futuro juízo de mérito. Ora, por isso mesmo esse tipo de receio de lesão só pode ser prevenido com a antecipação dos efeitos da própria sentença final. ${ }^{1}$

1. CALAMANDREI, em 1934, na sua clássica obra a respeito dos prowedimenti cautelari, Introduzione allo Studio Sistematico dei Prowedimenti Cautelari, agora in Opere Giuridiche, Morano, Napoli (1983), IX, nn 18, p. 196, havia advertido o fenómeno, ressaltando que, em alguns casos, a providência interina trata de "acelerar", em via provisória, a satisfação do direito. 
No entanto, e esse é o ponto que vem passando inadvertido, a antecipação pode se dar no âmbito do processo provisional sem necessidade de uma invocação precisa e detalhada do receio de lesão, e com muito maior adequação, dado que, como já foi ressaltado, a urgência está no cerne mesmo do direito de família. Aí é que pode entrar em cena o emprego das chamadas medidas provisionais, que não se ostentam nem cautelares nem provisórias, no âmbito de um procedimento sumário e autônomo capaz até de produzir coisa julgada material, como a seu tempo será demonstrado.

2. A quem se debruçar na análise do processo provisional, verificará tratar-se de providências vinculadas a uma porção do litígio extraído da vida real com origem no casamento, na união estável ou na filiação, em que cresce de intensidade a necessida de de pronta resposta jurisdicional, em face da natureza dos valores envolvidos, a mais das vezes mediante regulação das relações familiares. Essas duas noções, porção do todo e regulação de relações, não podem ser esquecidas. De momento, apenas registro sua importância.

No direito brasileiro, os artigos 888 e 889 do Código de Processo Civil cuidam da matéria relativa ao regramento legislativo das ações ${ }^{2}$ provisionais. O problema, como se verá a seu devido tempo, é equacionado mediante um processo formalmente sumário e autônomo, vale dizer, despegado da necessidade de propositura futura de uma demanda dita principal, ao contrário do que sucede com as típicas ações cautelares. Realmente, em relação a estas o sistema adotado pelo Código exige seja proposta a ação principal no prazo de 30 (trinta) dias, contados da efetivação da medida cautelar, se concedida de forma antecedente (artigo 806, combinado com o artigo 808, I).

O exame dos casos relacionados no artigo 888 deixa claro que, à exceção das obras de conservação em coisa litigiosa ou judicialmente apreendida, hipótese prevista no inciso I, as demais providências compreendem tutela de pretensões de natureza predominantemente não-patrimonial, configurando obrigações de feição infungível, sem sucedâneo adequado em pecúnia. Como sub-rogar em caução a posse provisória dos filhos ou o afastamento do menor autorizado a contrair casamento contra a vontade dos pais? Qual a forma de prevenir o dano moral ou físico a menores ou incapazes, senão antecipando a sentença final? Que princípio jurídico poderia constranger espíritos inconciliáveis a convívio forçado? Em que aproveita a cominação de pena a quem infringir, v.g., os cuidados nese coletivo, de maior hierarquia, impõe a paralisação imediata do gravame à população? Dinheiro algum, mesmo em relação à espécie do inciso II do artigo 888 , poderia substituir o valor afetivo dos bens de uso pessoal do cônjuge e dos filhos, tolerado o ressarcimento em moeda apenas com caráter de excepcionalidade. cessários com a saúde pública, se o interes-

2. A nota distintiva da autonomia já indica a impropriedade de se denominar "medida" o que na verdade se apresenta como típica ação.

Revista da Faculdade de Direito da UFRGS, v. 18, 2000
Essas circunstâncias bem demonstram, na base de tais remédios jurídicos, a presença de direitos essencialmente vinculados a valores não traduzíveis em pecúnia, expressões de momentos de liberdade - formal ou substancial - ou, ainda, destinados a atender necessidades primárias. Fácil é compreender, por isso mesmo, que a nãosatisfação antecipada de tais pretensões acarretaria, por hipótese, prejuízo irreparável, revelando-se quase sempre impossível ou inadequado o ressarcimento mediante equivalente monetário. Vale dizer, portanto, que tais pretensões melhor serão atendidas mediante uma tutela de tipo preventivo do que reparatório.

Em assim sendo, ante o manifesto interesse público ou de ordem pública de que se revestem, essas situações impõemse resolvidas por meio de tutela jurisdicional especial, de caráter sumário e urgente, em contraposição ao demorado procedimento comum, previsto geralmente em nosso sistema jurídico para o processo de conhecimento normal.

Deve ainda ser observado que, conquanto a providência estatuída no inciso II do artigo 888 (entrega de bens de uso pessoal do cônjuge e dos filhos) esteja preordenada para a satisfação imediata de uma pretensão - adquirindo assim feição executiva lato sensu -, as demais, cuidando de relações jurídicas de duração, encontram solução mais adequada na própria estruturação da relação, o que se traduz pela regulação judicial da situação conflituosa. Importa dizer que a atuação do órgão judicial não será pontual, destinada apenas a resolver uma crise imediata e localizada, mas sim de longo alcance e espectro, buscando estabelecer em base amplas um convívio mais duradouro, com vistas a uma relação não conflituosa, embora divergente.

A simples enumeração das hipóteses possíveis põe a claro o que se afirmou: posse provisória dos filhos, em separação judicial, divórcio ou anulação de casamento, ou em rescisão de união estável (artigo 888, inciso III); afastamento do menor autorizado a contrair casamento contra a vontade dos pais (artigo 888, inciso IV); depósito de menores ou incapazes castigados imoderadamente por seus pais, tutores ou curadores, ou por eles induzidos à prática de atos contrários à lei ou à moral (artigo 888 , inciso $\mathrm{V}$ ); afastamento temporário de um dos cônjuges ou conviventes da morada do casal (artigo 888, inciso VI); guarda e educação dos filhos (artigo 888, inciso VII, 1 a parte); regulação do direito de visita (artigo 888 , inciso VII, 2ª parte).

3. Em tais casos, como se constata da enumeração acima realizada, a lide total diz respeito à ação de separação ou de divórcio dos cônjuges, ou de rescisão da convivência dos companheiros, em que juntamente com a pretensão principal de natureza constitutiva convivem outras pretensões.

Além disso, deve ser ponderado que embora pudesse o problema em seu todo ser resolvido de uma só vez e numa só demanda, nada impede permita o legislador, atento aos valores envolvidos, a solução parcial da contenda.

Aliás, a observação do que mais ocorre recomenda uma solução parcial do conflito. Por um lado, pode se tornar demasiadamente complicada a solução do 
litígio na sua inteireza, de uma só penada. Por outro, muitas vezes, e o fenômeno não é raro em direito de família, não se verifica ainda a maturação emocional necessária para o equacionamento total do conflito, e o problema deve ser resolvido progressivamente por etapas, a exigir fases sucessivas de acomodação de todos os interessados (pais e filhos, marido e mulher, tutores, conviventes, etc.).

Em atenção a essas circunstâncias, o legislador brasileiro inclinou-se, sem dúvida alguma, no sentido de atender a tais valores por processo especial sumário e não-cautelar. A exclusão a meu ver foi deliberada porquanto, como decorre da expressa determinação contida no artigo 889 , no processo provisional deve ser observado apenas o procedimento das ações cautelares, estabelecido nos artigos 801 a 803 . De mais a mais, a regra contida no artigo 889 mostrar-se-ia evidentemente inútil, se enquadrado o fenômeno na categoria do processo cautelar, face ao disposto no artigo 812 , que remete aos mesmos dispositivos, e exatamente com vistas aos procedimentos cautelares específicos.

O quadro estabelecido pelo legislador, acima esboçado, permite extrair desde logo algumas conclusões relevantes para o tema em exame. A mais importante talvez seja a de que não estamos diante da provisoriedade própria do processo cautelar ou da medida antecipatória, cujos efeitos estão fadados a se subsumir no julgamento do processo principal.

A dificuldade semântica, pela polissemia própria da linguagem, encontrada principalmente das línguas ricas e altamente desenvolvidas, habita na circunstância de que a lei não fala em provisório, mas em "provisional". E "provisional" exibe na língua sentido ambíguo e equívoco, pois é relativo também à qualidade de provisório. A primeira acepção (provisional), ligada a provisão (antes de tudo provimento, ato ou efeito de prover) vale dizer, tomar providências, regular, ordenar, fornecer, sentido esse já detectado na língua no século XIII, é bem mais antiga que a segunda (provisório), dicionarizada somente no século XIX, derivada do latim medieval provisorius. Embora em contexto totalmente diverso, dificuldade de igual monta atormenta os processualistas italianos na compreensão da provvisionale do artigo 278 do CPC peninsular, concebida pela doutrina, de modo geral, não como providência provisória cautelar, mas como pronunciamento definitivo parcial (Teilurteil do direito alemão) sobre a porção do crédito em torno do qual tenha o juiz elementos probatórios suficientes. ${ }^{3}$

Em realidade, com maior ou menor intensidade, nas espécies contidas nos diversos incisos do artigo 888 tende-se à regulação de alguma relação jurídica material, sem dependência a outro processo, dito principal. A existência de outro processo, compreenda-se, pode mesmo se verificar, mas é irrelevante, porque a sentença profe-

3. Ct. a propósito, CALAMANDREI, Introduzione allo Studio Sistematico. In Opere Giuridiche, cit., vol. IX, nº 31, pp. 222/224. FEDERICO CARPI, La Prowisoria Esecutorietà della Sentenza, p. 167 e nota 65, advertira inclusive a questão terminológica, acenando com a crenca de que mais do que o provisorio, encontra-se na raiz de provisionale o sentido de provision, em que está inito conceito de execuç̧̃o imediata.

Revista da Faculdade de Direito da UFRGS, v. 18, 2000 rida no processo de cunho provisional não está fadada a se subsumir na sentença da demanda principal, como ocorreria na hipótese de típica e veraz ação cautelar.

Verifica-se, portanto, trabalhar o caput do artigo 888 com um conceito de ação principal que guarda pouco ou nenhum ponto de contato com a mesma expressão contida no artigo 796. "Ação principal" constitui, aqui, apenas a demanda em que se discutirá o restante da relação material litigiosa, a exemplo da separação litigiosa do casal, aforada depois de proposta a ação provisional de guarda e educação dos filhos, com a respectiva regulação do direito de visita.

Por isso mesmo, o fato de o autor deixar de ajuizar a separação litigiosa do casal, no prazo de trinta dias, depois de efetivada a guarda do filho, e o ponto é assaz significativo, não acarretará a extinção do processo provisional. $\mathrm{O}$ artigo 808 só vigora para o processo cautelar, não para o provisional, como decorre, inclusive dentro de uma perspectiva hermenêutica puramente sistemática, do artigo 889. Aquela determinada solução continuará vigendo para a porção da relação jurídica substancial litigiosa resolvida pelo órgão judicial, porção essa de per se relevante no mundo jurídico (o exemplo típico é o da separação de corpos, que hodiernamente constitui em si mesma um valor nada desprezível).

4. Outro aspecto sobremaneira importante diz respeito à natureza da cognição exercida no processo provisional e no exame da liminar nele exarada.

Determina o artigo 889 a observância, na aplicação das "medidas provisionais", do procedimento estabelecido nos artigos 801 a 803.

Daí decorre, em primeiro lugar, a necessidade de se introduzir o processo provisional mediante petição escrita, com os requisitos estabelecidos no artigo 801 .

A exigência contida no inciso III do artigo 801 deverá ser adaptada às peculiaridades do procedimento: por "lide e seu fundamento" entender-se-á a relação jurídica material total, na qual se insere a parcela a ser resolvida na provisional.

Impõe-se, logo a seguir, a citação do demandado para contestar (rectius: responder) aos termos do pedido em 5 (cinco) dias e indicar as provas que pretende produzir (artigo 802). O prazo conta-se da juntada aos autos do mandado de citação devidamente cumprido (artigo 802, parágrafo único, inciso I) ou da realização da providência que, em caso de urgência, tiver sido deferida sem audiência do requerido (artigo 802, parágrafo único, inciso II combinado com o artigo 889, parágrafo único).

Não sendo contestado o pedido, presumir-se-ão aceitos pelo demandado, como verdadeiros, os fatos alegados pelo demandante; caso em que o juiz decidirá dentro de 5 (cinco) dias (artigo 803).

Se o demandado contestar no prazo legal, o juiz designará audiência de instrução e julgamento, havendo prova a ser nela produzida (artigo 803, parágrafo único)

A enumeração das circunstâncias que foram definidas em lei, para a demonstração probatória das alegações de fato no processo provisional, demonstra por si só 
classificar-se a cognição nele exercida como formalmente sumária, pois nenhuma restrição se coloca quanto à matéria a ser apreciada pelo órgão judicial, a não ser aquelas decorrentes dos limites impostos pelo pedido e pela causa de pedir, dentro do âmbito estabelecido pelo autor da ação, conjugado com as exceções de direito material opostas pelo demandado.

A respeito dessa matéria, impõe-se mencionar a elaboração dogmática de HANS KARL BRIEGLEB, a quem coube o mérito indiscutível de ter, já em 1859, distinguido a mera simplificação formal do processo da sumariedade material. Segundo sua doutrina, o processo verdadeiramente sumário caracteriza-se pela incompletude material da causa cognitio, por meio da exclusão dos meios ordinários de defesa, circunstância que vem a se refletir no efeito provisório da decisão daí resultante.

De sua vez, o procedimento acelerado, cuja origem está nas fontes do direito canônico (especialmente na Decretal Saepe contingit do Papa Clemente III, de 1306), distingue-se pela forma encurtada, simplificada e concentrada do procedimento, mas não pela incompletude da cognição e muito menos pelo seu imperfeito resultado (provisoriedade)

Assim, o processo acelerado distingue-se do ordinário pela forma e do sumário pelo material em debate no litígio. Não

são, portanto, da mesma espécie nem formas diferentes. Mesmo quando ocorrem no processo sumário atos processuais cuja forma e ordenação parecem um desvio da forma comum do procedimento, constitui isto apenas uma conseqüência secundária do princípio material característico da cognição sumária. ${ }^{4}$

Incorporando-se essa lição, de induvidosa correção, ao direito brasileiro atual, o impropriamente denominado processo sumário (rectius: acelerado), ${ }^{5}$ regulado nos artigos 275 a 281, assim como o processo provisional de que tratam os artigos 888 e 889 do Código, nada mais constituem do que aceleração do procedimento ordinário (fenômeno que a doutrina atual convencionou denominar de sumariedade formal). Nada obstante isso, a cognição revela-se plena e exauriente, da mesma maneira como ocorre no procedimento ordinário. Por isso mesmo, o provimento jurisdicional equacionador da controvérsia reveste-se de probabilidade em grau suficiente para se tornar imutável e livre de ataques futuros em qualquer outro processo, como se verá no tópico seguinte deste ensaio.

Interessante é comparar o que se passa com o processo cautelar em sentido estrito. Embora exiba este, praticamente, a mesma estrutura do sumário formal, nele a cognição do juiz se circunscreve ao objeto

4. BRIEGLEB, Einleitung in die Theorie der Summarischen Processe, Leipzig, Tauchnitz, 1859, §4, pp. 11/13, passim. Essas idéias tiveram depois desenvolvimento

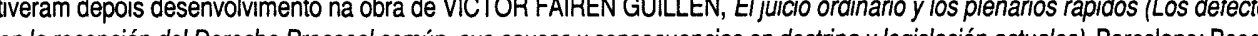
1953, e, entre nós, na tese de doutoramento de KAZUO WATANABE. Da cogniçãoo no processo civil. São Paulo: RT, 1987,

5. Pelos menos idealmente, visto que a prática brasileira demonstra quase que uma total inaptidão do dito processo sumário a alcançar sua finalidade em tempo mais rápido do que gasto normalmente no procedimento ordinário.

Revista da Faculdade de Direito da UFRGS, v. 18, 2000 específico deste tipo de tutela jurisdicional, dirigida apenas a prevenir o dano em face de risco a provável direito do autor. Constata-se no processo cautelar, por conseguinte, sumariedade de tipo material, em face da cognição necessariamente incompleta do material a ser trabalhado pelo órgão judicial, conquanto exauriente no que se refere à profundidade.

Merece outras considerações a cognição desenvolvida pelo órgão judicial ao momento de exarar a decisão liminar facultada no parágrafo único do artigo 889 - cognição essa que os romanos chamavam com propriedade de prima facie ${ }^{6}$-, fenômeno comum a todo tipo de tutela de urgência. Aqui, mostra-se preciso distinguir o juízo sobre a aparência do bom direito do juízo referente ao periculum in mora.

No concernente ao periculum, o aspecto decisivo para uma compreensão exata do que se passa deve ser buscado na própria finalidade da decisão liminar, que não é destinada a prevenir um receio de lesão pontual. Não, a lei, em perfeita adequação com o objeto do processo provisional, emprega de maneira muito eloqüente a expressão "urgência", conceito de muito maior amplitude e que leva em conta a necessidade de solucionar-se rapidamente questões dessa ordem, em virtude da própria natureza dos valores nãopatrimoniais em jogo.

Estamos aqui, como já se ressaltou com grande autoridade, embora em outro contexto, diante do verdadeiro e autêntico

periculum in mora, cujo conceito na tradição do direito medieval dizia respeito a certas causas que, por sua simplicidade ou relevância, ou mesmo pela urgência com que exigiam uma pronta resposta jurisdicional, recomendavam um tratamento sumário. Não se cuida de um receio de lesão decorrente da possibilidade de um damnum irreparabile, em que a resposta jurisdicional nada tem a ver com a natureza da causa, mas com a irrupção de um elemento ocasional de risco de dano iminente, capaz de ocorrer, em princípio, com relação a qualquer tipo de causa.?

Daí decorre, em vista da própria natureza dos valores envolvidos, que a urgência em regra é pressuposta em caso de tutela provisional, de modo a ser dispensada, em relação a ela, a exibição da "prova inequívoca" reclamada no caput do art. 273. Em conseqüência, basta tão-somente resulte no espírito do julgador, da exposição dos fatos realizada pelo autor na petição inicial, a convicção de verossimilhança do alegado perigo na demora.

No que concerne à aparência do bom direito, trata-se indubitavelmente de sumariedade tanto material quanto superficial ou baseada na aparência. Sumária do ponto de vista material, porquanto restrita à urgência; de aparência ou superficial, por se bastar com o aporte fático e probatório do autor, em matéria ainda não submetida ao contraditório, embora no horizonte da chamada prova inequívoca, aplicável por analogia o disposto no caput do artigo 273. Reclama-se algo mais do que na tutela

Briegleb, ob. cit., pp. 238/266, enumera algumas hipóteses interessantes.

7. Cf. a precisa e erudita apreciação de Ovidio A. Baptista da Silva. Do Processo Cautelar. Rio de Janeiro: Forense, 1996, p. 12. 
cautelar e certamente menos do que na tutela dispensada em cognição plena e exauriente. A exigência de prova inequívoca, mesmo sem expressa determinação legal, no caso da provisional, explica-se em razão da intromissão da ordem no próprio direito material, com conseqüências bem mais profundas do que ocorre com uma providência de cunho cautelar e, portanto, de natureza meramente assecuratória.

Note-se que na tutela cautelar, mesmo sem qualquer prova, pela simples exposição dos fatos da causa, pode o juiz, em se convencendo da verossimilhança do direito alegado e do receio de lesão, dispensar cautela liminarmente. Na antecipatória, no entanto, indispensável se torna "prova inequívoca", vale dizer, clara, sem jaça, evidente, mas quanto baste para o convencimento da probabilidade da alegação e não da sua certeza (a certeza, aliás, mostra-se sempre relativa em direito processual, como sabido). Assim, tanto pode atender ao modelo legal um começo de prova por escrito, como a justificação prévia. $O$ mesmo sucede no processo provisional, no que tange ao provável direito.

De qualquer modo, tanto em relação ao perigo na demora quanto à aparência do bom direito, a cognição continua sendo incompleta, não exauriente: nada impede, por exemplo, venha a ser provado no curso do processo que determinada alegação fática, a princípio considerada evidente, não corresponda exatamente à realidade.

Mesmo a prova documental initio litis não retira à cognição prima facie, no exame

do pedido de liminar, a sua condição de sumária, pois continua a trabalhar com a aparência, ainda sujeita ao crivo do contraditório, e a instrução poderá demonstrar a falsidade do elemento que servira de base à convicção inicial do órgão judicial.

Cumpre ainda ressaltar que o requisito negativo da irreversibilidade dos efeitos da antecipação, estatuído no $\S 2^{\circ}$ do artigo 273 , raramente poderá ser invocado na apreciação da liminar no processo provisional. A meu ver, restrição generalizada e indistinta dessa ordem trata o problema de forma míope, por privilegiar demasiadamente e de forma engessada o ponto de vista da parte demandada em detrimento do autor da providência. Este também pode estar em risco de sofrer prejuízo irreparável, em virtude de irreversibilidade fáctica de alguma situação da vida. Só o órgão judicial está habilitado para apreciar o conflito de valores no caso concreto, sempre presente por sinal em qualquer problema humano, e dar-lhe solução adequada. Essas situações, note-se, tendem a ocorrer com freqüência nas matérias ligadas ao direito de família e nem a lei quando tratava o problema de maneira estrita, sob a ótica da cautelar nominada, impunha qualquer restrição (ver, por exemplo, a regulação dos alimentos "provisionais" estabelecida no artigo 852).

Conquanto se possa afirmar a priori tenha o legislador estabelecido uma relação específica de prevalência do direito fundamental à efetividade do processo sobre o da segurança jurídica, ${ }^{8}$ mesmo assim hipó-

8. Cf., Teori Albino Zavascki no excelente ensaio intitulado Antecipação de Tutela e Colisão de Direitos Fundamentais. In Ajuris, 64 (jul/.95):395-417, esp. p. 402

teses haverá em que o juiz haverá de ponderar, em face das circunstâncias específicas do caso concreto, a melhor maneira de harmonizar eventualmente o conflito axiológico entre a garantia de acesso à jurisdição (art. 5ํ, XXXVI, da Constituição) e a garantia do contraditório e da ampla defesa (art. 5ำ LV, da Constituição).

Pense-se, por exemplo, na hipótese de não ser concedida ordem liminar pela possibilidade de ser causado um dano irreversível na situação fática de interesse do demandado e a sua vez o requerente da providência esteja em risco de padecer um dano igualmente de natureza irreversível. Aí o conflito axiológico imporia uma minudente ponderação das circunstâncias do caso concreto, de molde a permitir, estando presente o pressuposto da aparência do direito, o sacrifício do direito improvável no altar do direito provável. Insista-se em que a restrição contida no mencionado $\S 2^{9}$ do art. 273 do CPC, não pode afastar tal conclusão porque o poder do legislador infraconstitucional não chega ao ponto de pretender interferir em direitos fundamentais, reduzindo ou enfraquecendo algum em detrimento de outro. $O$ conflito, por isso mesmo, só pode ser equacionado pela aplicação do princípio da proporcionalidade, que consiste em assegurar a eficácia dos direitos e em dar proteção aos interesses daí

decorrentes, mediante a técnica da ponde ração dos valores e o equilíbrio dos interes. ses em jogo no caso concreto. ${ }^{9} \mathrm{E}$ um elemento decisivo, sem dúvida, nesse contexto, é a prevalência do direito provável.

5. Finalmente, é de ser examinado se o julgamento realizado no processo sumário autônomo do art. 888 pode ser coberto pelo chamado manto da coisa julgada material.

A análise do que se passa evidencia cuidar-se de sentença parcial de mérito, que não é "provisória", mas "provisional", proferida em processo em que, como antes demonstrado, a cognição revela-se plena e exauriente. A única diferença é que a sentença incidirá apenas sobre a porção do litígio trazida ao conhecimento do órgão judicial, sendo no entanto equiparável a qualquer outra sentença definitiva. ${ }^{10}$ Para tanto, basta que haja divisibilidade do objeto do litígio, como sucede nas hipóteses previstas no art. 888, já enumeradas no início deste trabalho.

Dentro dessas coordenadas, não há dúvida de que a sentença proferida no processo provisional estará apta a produzir coisa julgada material.

Naturalmente, poderá variar no curso do tempo a situação que fora contemplada na sentença, o que abriria a possibilidade de um novo pronunciamento

9. A respeito do princípio da proporcionalidade são valiosas, embora desenvolvidas na perspectiva do processo penal, as conside raçōes de Nicolas Gonzalez-Cuellar Serrano, Proporcionalidad y Derechos Fundamentales en el Proceso Penal, Madrid: Colex 1990, passim.

10. Esse entendimento é pacifico na doutrina italiana, cf., por todos, Federico Carpi, La prowisoria esecutorietà, cit,, pp. 167-168, e Roberto Marengo, Provvisionale, verbete in Enciclopedia del Diritto, Milano, Giuftrè, 1988, pp. 888/892, esp. p. 891. Assim também na doutrina alemã: v.g., Rosenberg-Schwab, Zivilprozessrecht, 12. Auflage, München, Beck, 1977, \$ 58, II, 2 pp. 292/294, Wolfgang Grunsky, Grundlagen des Verfahrensrechts - Eine vergleichende Darstellung von ZPO FGG, VwGO, FGO, $S G G$ 2.neuaberteitete Auflage, Bielefeld, Gieseking, 1974, §46, 2, pp. 465-466, Fritz Baur, Zivilprozessrecht, Frankfurt a. M., Metzner $1985, \S 17$, III, 1, d, p. 208 
judicial. Nesse caso, contudo, como é evidente, não estaria em risco a autoridade da coisa julgada material da primeira sentença, que sempre pressupõe mesmeidade do objeto litigioso e das partes (art. 301, §§ $1^{\text {o }}$ e 2ํdo CPC). Cuida-se de situação análoga a que resulta do exercício da ação de alimentos. Mesmo a introdução na Lei $\mathrm{n}^{\mathrm{o}}$ 5.478, de 25.07.1968, de uma norma como a do art. 15 , a determinar que "A decisão judicial sobre alimentos não transita em julgado e pode a qualquer tempo ser revista em face da modificação da situação finan ceira dos interessados", não muda os termos do problema. Como bem se demonstrou em sede doutrinária, trata-se de manifesta impropriedade, pois seria impraticável a emissão de nova sentença relativamente à mesma situação contemplada na outra, como, por exemplo, se o condenado à prestação alimentar viesse a pleitear a declaração judicial de que, já ao tempo da primeira sentença, ele nada devia a esse título. ${ }^{11}$
11. J. C. Barbosa Moreira, Eficácia da sentença e autoridade da coisa julgada. In Ajuris, 28 (julho/1983):15-31, esp. pp. 29-30 Revista da Faculdade de Direito da UFRGS, v. 18, 2000

\title{
Proposta de uma Teoria Geral dos Serviços com Base no Código de Defesa do Consumidor - A Evolução das Obrigações Envolvendo Serviços Remunerados Direta ou Indiretamente
}

\author{
Claudia Lima e Maxques \\ Professora da Universidade Federal do Rio Grande do Sul. Doutora em Direito pela \\ Universidade de Heidelberg, Alemanha. Diretora do BRASILCON-Instituto Brasileiro
} de Política e Direito do Consumidor 1998-2000.

\section{Introdução}

Ê

em sentido, afirmativo, que aceito o desafio proposto por ANTÔNIO HERMAN BENJAMIN $\mathrm{e}$ ALBERTO AMARAL JÚNIOR que, ao organizarem o "XVII Curso Brasilcon de Direito do Consumidor: $O$ Consumidor e o Mercado de Serviços", pediram-me para elaborar uma "Teoria Geral dos Serviços" com base nas normas e princípios do Código de Defesa do Consumidor (CDC). As importâncias do tema "serviços" no mercado atual dispensa comentários, mas é certo que o momento fragmentário atual não é o mais propício para elaborar teorias gerais. ${ }^{1}$ Da mesma forma, analisar em um artigo

1. Em 1997, Luciano Timm defendeu no Mestrado da UFRGS dissertação intitulada Teoria Geral da Prestação de Serviços, publicada pela LTr., TIMM, Luciano B., Da Prestação de Serviços, Ed. Sintese, Porto Alegre, 1998.

Revista da Faculdade de Direito da UFRGS, v. 18, 2000 somente os serviços de consumo e o CDC, sem considerar o Projeto de Código Civil de 1975, que expressamente prevê uma categoria de contratos de prestação de serviços, restringe o alcance deste estudo e de qualquer esforço generalizante. Parece-me, porém, que evoluir para uma visão geral e atualizadora do aspecto talvez mais interes. sante e renovador do CDC, que é justamente a aproximação quase igualitária dos regimes das obrigações de dar e de fazer, seria uma contribuição "reconstrutora" válida.

Segundo PAULINE MARIE ROSENAU, com a atual crise das ciências
sociais, dois tipos de reações estão acon- 